\title{
Kernos
}

Revue internationale et pluridisciplinaire de religion grecque antique

$13 \mid 2000$

Varia

\section{Irad MALKIN, La Méditerranée spartiate. Mythe et territoire}

\section{Vinciane Pirenne-Delforge}

\section{OpenEdition \\ Journals}

\section{Édition électronique}

URL : http://journals.openedition.org/kernos/1328

DOI : $10.4000 /$ kernos. 1328

ISSN : 2034-7871

\section{Éditeur}

Centre international d'étude de la religion grecque antique

Édition imprimée

Date de publication : 1 janvier 2000

ISSN : 0776-3824

\section{Référence électronique}

Vinciane Pirenne-Delforge, «Irad MALKIN, La Méditerranée spartiate. Mythe et territoire », Kernos [En ligne], 13 | 2000, mis en ligne le 21 avril 2011, consulté le 21 septembre 2020. URL : http:// journals.openedition.org/kernos/1328; DOI : https://doi.org/10.4000/kernos.1328 
Le dernier cas de nostos examiné, celui de Diomède (ch. 8), est une démonstration de la complexité des fonctions de ce type de récits et de l'impossibilité d'une explication unifiante. Répondant à l'idée d'un syncrétisme avec les héros locaux, I.M. valorise à raison les témoignages grecs archaïques pour postuler que Diomède est arrivé non pas en tant que héros illyrien mais en tant que héros grec en Adriatique, aussi tôt que le vır ${ }^{\mathrm{e}}$ siècle, avec une perspective d'exploration maritime au début, sans projet de colonisation. Du point de vue grec, Diomède est un héros relativement marginal, "représentant " d'une koinê régionale du nord-ouest (Étolie), qui n'est pas associé à un lieu à signification panhellénique comme Ithaque ou à une épopée comme l'Odyssée. Néanmoins, son rôle dans l'Adriatique est impressionant, notamment parmi les non-Grecs, récupéré plus tardivement par les Grecs, souvent dans un esprit de justification et de légitimation mais aussi comme expression des frustrations et des échecs des colonisateurs.

Nombre de thèmes traités par I.M. sont abordés dans le nouveau livre d'Alain Ballabriga, dans un esprit très différent : Strabon contre Ératosthène, datation plus basse de l'adoption de l'alphabet et de la fixation des poèmes homériques, une autre évaluation de la coupe de Nestor de Pithekoussai et plus généralement des notions de la tradition, de l'oralité, de l'intertextualité (Les fictions d'Homère. L'invention mythologique et cosmographique dans l'Odyssée, Paris, PUF, 1998). En ce qui concerne l'ethnicité et les Grecs, on remarquera que I.M. ne met pas en perspective son postulat d'une cuvre homérique dépourvue d'un concept unifiant concernant les Grecs avec l'idée désormais établie d'une épopée homé rique à dessein panhellénique, à une époque de contacts intenses entre les élites des cités grecques (A. Snodgrass, G. Nagy). Comme le constate E. Lévy, après un examen détaillé du langage homérique à ce propos, "on ne peut pas dire que l'Iliade ignore la Grèce et les Grecs » (Apparition des notions de Grèce et de

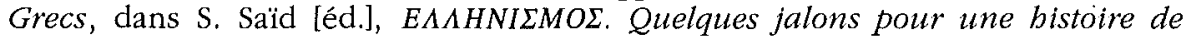
l'identité grecque, Actes du Colloque de Strasbourg, 25-27 oct., 1989, Leiden, Brill, 1991). Par ailleurs, signalons l'usage parfois détournée du mot nostos - « le retour » et «les récits sur les retours »- pouvant induire l'idée que nostos est aussi le héros qui retourne.

De même que la période de la protocolonisation qu'il examine, le livre de I.M. est un livre d'ouverture et d'exploration de nouveaux chemins de recherche. Si les données sont parfois trop évasives, si des grandes questions non résolues notamment dans le domaine homérique - pendent comme une épée de Damoclès sur certaines hypothèses, l'effort de reconstruction est prudent et très documenté, plaidoyer très réussi d'une approche interdisciplinaire, aussi indispensable que peu pratiquée de cette façon, pour attaquer avec résolution cette période où tout a pris forme, les dieux et les cités des Grecs.

Ioanna Papadopoulou-Belmehdi (Université Libre de Bruxelles)

Irad MaLkin, La Méditerranée spartiate. Mythe et territoire, traduit par Odile Meslier, Paris, Les Belles Lettres, 1999. 1 vol. $15 \times 21,5 \mathrm{~cm}, 395$ p. (Coll. Histoire). ISBN : 2-251-38041-8.

Le titre de cet ouvrage est sans doute volontairement provocant: Sparte ne relève pas, à première vue, de la catégorie des grandes cités coloniales de l'époque archaïque. Mais les analyses minutieuses de l'A. ouvrent avec brio les horizons de la "colonisation spartiate ", bien plus larges, notamment sur le plan symbolique, que les seules Tarente (706 av. J.-C.) et Héraclée de Trachis ( 426 av. J.-C.). 
Au centre de cette "Méditerranée spartiate » comprenant notamment Mélos, Théra, les Crétoises Lyktos et Gortyne, Cyrène, Cnide, Crotone, Locres et Éryx, mais aussi les implantations dans le Péloponnèse, se trouve Sparte elle-même, conçue comme "la colonie " fondée conjointement par les Doriens et les descendants d'Héraclès. Ce n'est pas le moindre intérêt de ce livre foisonnant que dę penser l'établissement de chaque colonie en rapport avec la question du pouvoir à Sparte et de la difficulté d'intégration de certains groupes qui doivent se résoudre à la quitter. L'introduction définit d'emblée l'angle d'approche du thème : l'A. veut fournir une étude historique qui dépasse les paramètres de la seule « histoire des mentalités » en «s'interrogeant sur la manière dont les Grecs formulaient, par le biais des mythes, le rapport qu'ils entretenaient aux lieux où ils s'implantaient »; ou encore " les mythes nationaux n'ont pas besoin d'être vrais au sens positiviste du mot pour être efficaces et avoir du poids - c'est la thèse majeure de ce livre » (p. 12-13). Mais l'historien est très conscient que le mythe a d'autant plus de chance d'être efficace qu'il se fonde sur un événement «vrai ». L'A. propose dès lors un va et vient constant entre le poids symbolique du récit mythique et le noyau de «vérité » qui pourrait bien s'y trouver, plus ou moins déformé ( $c f$. p. 64, 91, 95, 105-107, 171, etc.).

Le premier chapitre traite du mythe constitutif de la fondation de Sparte, à savoir le retour des Héraclides, qui rompt avec un passé primordial - auquel appartiennent les héros homériques qui ont régné sur la région - et fait, in fine, de la Sparte dorienne une nation «jeune ». La distinction est faite entre les Héraclides et les Doriens : la saga des Héraclides a existé indépendamment des Doriens censés avoir accompagné le «Retour» dans le Péloponnèse. Le deuxiëme chapitre traite de Ménélas et de l'exploitation de sa figure dans certains mythes « d'ouverture » de la terre à coloniser, tant en Cyrénaïque qu'en GrandeGrèce et en Sicile. C'est dans le troisième chapitre que se marque sans doute le plus la tension entre mythe et "réalité-vérité »: l'étude des colonies égéennes, entre autres Mélos et surtout Théra, tente en fait de mettre au jour la «base réelle » de la colonisation pour expliquer la force de la croyance au mythe. Les trois chapitres suivants étaient attendus puisqu'ils étudient tout ce qui a trait à Tarente, la plus connue des colonies spartiates, et à Cyrène, «petite-fille " coloniale de Sparte par l'intermédiaire de Théra. Le traitement des cultes d'Apollon Carnéios et Zeus Ammon illustre bien l'importance de la dimension cultuelle dans le rapport entre la métropole et les colonies. En outre, l'A. voit dans l'Apollon Carnéios l'archégète par excellence, ce qui est assurément neuf. Les deux derniers chapitres s'ancrent davantage dans l'histoire et doivent permettre, par l'analyse des fondations avortées de Dorieus et celle de la brève implantation d'une Héraclée près de Trachis, d'approcher - avec davantage de certitudes que dans le cas des fondations du haut archaïsme - le fonctionnement du mythe dans l'imaginaire politique des Spartiates. Car là se trouve évidemment la difficulté essentielle de l'entreprise d'Irad Malkin : les sources sur lesquelles appuyer les - reconstructions historico-mythiques de la période archaïque sont désespérément tardives et bien des démonstrations, en dépit de l'indéniable rigueur et de la remarquable information du travail, restent extrêmement hypothétiques.

Publié en anglais en 1994, l'ouvrage est donc désormais disponible dans une bonne traduction française. On ne déplorera jamais assez, cependant, cette manie éditoriale de reléguer les notes en fin de volume, surtout pour des ouvrages où l'appareil justificatif est indispensable à la bonne intelligence de l'exposé et ne se réduit pas à un jeu érudit facultatif ! 